\title{
The mean meridional circulation and midlatitude ozone buildup
}

\author{
G. Nikulin ${ }^{1}$ and A. Karpechko ${ }^{2}$ \\ ${ }^{1}$ Swedish Institute of Space Physics, Atmospheric Research Programme, Box 812, 98128 Kiruna, Sweden \\ ${ }^{2}$ Finnish Meteorological Institute, Arctic Research Centre, Tähteläntie 62, 99600 Sodankylä, Finland
}

Received: 9 May 2005 - Published in Atmos. Chem. Phys. Discuss.: 30 June 2005

Revised: 18 October 2005 - Accepted: 9 November 2005 - Published: 24 November 2005

\begin{abstract}
The wintertime ozone buildup over the Northern Hemisphere $(\mathrm{NH})$ midlatitudes and its connection with the mean meridional circulation in the stratosphere are examined statistically on a monthly basis from October to March (1980-2002). The ozone buildup begins locally in October with positive total ozone tendencies over the North Pacific, which spread eastward and westward in November and finally cover all midlatitudes in December. The local onset of the buildup in October is not evident in zonal mean ozone tendency, which is close to zero. From November to March, zonal mean total ozone tendency $\left(50^{\circ}-60^{\circ} \mathrm{N}\right)$ shows a strong correlation $(|\mathrm{r}|=0.7)$ with several zonal mean parameters associated to the mean meridional circulation, namely: eddy heat flux, temperature tendency, the vertical residual velocity and the residual streamfunction. At the same time, on the latitude-altitude cross section, correlation patterns between ozone tendency and widely used eddy heat flux are not uniform during winter. The strongest correlations are located equatorward (almost throughout the stratosphere) or poleward (only in the lower stratosphere) of the edge of the polar vortex. Such distribution may depend on the existence of the midlatitude and polar waveguides which defined refraction of upward propagating waves from the troposphere either to the midlatitude stratosphere or to the polar stratosphere. As a consequence of the nonuniform correlation patterns, heat flux averaged over the common region $45^{\circ}-75^{\circ} \mathrm{N}$, $100 \mathrm{hPa}$ is not always an optimum proxy for statistical models describing total ozone variability in midlatitudes. Other parameters approximating the strength of the mean meridional circulation have more uniform and stable correlation patterns with ozone tendency during winter. We show that the NH midlatitude ozone buildup has a stable statistical relationship with the mean meridional circulation in all months from October to March and half of the interannual variability
\end{abstract}

Correspondence to: G. Nikulin

(grigory@irf.se) in monthly ozone tendencies can be explained by applying different proxies of the mean meridional circulation.

\section{Introduction}

Since the early studies of Brewer (1949) and Dobson (1955) it has been recognized that the wintertime total ozone increase in extratropics results from the diabatic (BrewerDobson) circulation in the stratosphere. The zonal mean meridional circulation can be described by the Lagrangian mean approach (LM) or by the transformed Eulerian mean (TEM) approach which is more practical for estimating LM motions (Andrews et al., 1987). In the TEM formulation the residual circulation (as an approximation of Lagrangian motions projected on the meridional plane) is driven by waves, while divergence of the Eliassen-Palm (EP) flux represents a net wave forcing. The vertical component of the EP flux $\left(F_{z}\right)$, which is proportional to the zonal mean eddy heat flux $(\mathrm{HF})$, is widely used as a proxy of wave forcing of the residual circulation.

The connection between wave forcing and ozone variability has previously been demonstrated by several authors. Nagatani and Miller (1987) have found coherent variations between the $100 \mathrm{hPa} F_{z}$ during September and the $30 \mathrm{hPa}$ zonal mean ozone during October in the South Hemisphere (SH). The near-global structure of stratospheric ozone response to wave forcing during stratospheric warmings has been presented by Randel (1993). Fusco and Salby (1999) have shown that total ozone tendency $\left(\Delta \mathrm{O}_{3} / \Delta t\right)$ over the Northern Hemisphere (NH) extratropics in January strongly correlates with the $100 \mathrm{hPa} F_{z}$. Close correlation exists also between wintertime $\Delta \mathrm{O}_{3} / \Delta t$ averaged over middle and high latitudes and wave forcing accumulated during the winter (Salby and Callaghan, 2002; Weber et al., 2003). However, Randel et al. (2002a) found only weak correlations between midlatitude $\Delta \mathrm{O}_{3} / \Delta t$ and upward wave fluxes in

(C) 2005 Author(s). This work is licensed under a Creative Commons License. 
November-December in contrast to stronger correlations in January-March. Since midlatitude ozone buildup in the NH starts between October and November (Fioletov and Shepherd, 2003) and this is thought to result from the meridional stratospheric transport, the lack of strong correlations in November-December seems somewhat surprising.

The residual circulation in the stratosphere can be estimated from the net radiative heating rates using satellite observations (e.g. Solomon et al., 1986). Despite large uncertainties in the estimations (Eluszkiewich et al., 1996, 1997), there is a broad agreement between the residual circulations obtained from different data sources as well as between the circulations and theoretical expectations. The calculated circulations reproduce tropical upwelling and extratropical downwelling and also demonstrate stronger velocities in the northern winter circulation than in the southern one. That agrees well, at least qualitatively, with general concepts of the "extratropical pump" theory (see Holton et al., 1995; Plumb and Eluszkiewich, 1999). However, only a few studies have aimed to investigate direct statistical connections between the residual circulation and ozone. Geller et al. (1992) have shown positive correlations between the ozone mixing ratio and the vertical residual velocity above the ozone peak and negative correlations below the peak during DecemberFebruary for 1979-1986. They have also pointed out a delay of the wintertime total ozone maximum at $60^{\circ} \mathrm{N}$ relative to the vertical residual velocity maximum.

The present study aims at further exploration of the dynamical influence on the total ozone variability. The velocity of the residual circulation is a more straightforward proxy for the meridional stratospheric transport than HF though the latter is easier to derive. However, uncertainties in the diabatically-derived residual velocities may hamper its application as a dynamical proxy for total ozone. Here, the attempt is made to analyse in detail the relationship of $\mathrm{HF}$ and the residual circulation to the $\mathrm{NH}$ midlatitude total ozone month by month from October to March. Of particular interest is how well the diabatically-derived residual circulation can mirror interannual variability of wave forcing and ozone buildup. The study starts with an examination of the spacetime structure of monthly ozone tendencies and their relationship with HF. Then we demonstrate the connection between the residual velocities and wave forcing as represented by HF. Finally, we link ozone tendencies to the residual circulation.

\section{Data and method}

We use the version 8 of monthly TOMS/SBUV merged total ozone data (the $5^{\circ}$ zonal mean and $10^{\circ} \times 30^{\circ}$ gridded sets, http://code916.gsfc.nasa.gov/Data_services/merged) (Frith et al., 2004). The $50^{\circ}-60^{\circ} \mathrm{N}$ midlatitude region where ozone data is available in all winter months is chosen because $\Delta \mathrm{O}_{3} / \Delta t$ in this region correlates more strongly with both
$\mathrm{HF}$ and the residual circulation than in the more common $40^{\circ}-60^{\circ} \mathrm{N}$ region. In the $1990 \mathrm{~s}$ there are several years with missing zonal mean ozone data over $55^{\circ}-60^{\circ} \mathrm{N}$ in December (1992-1994, 1998) and January (1993-1995). Also there is no data over $50^{\circ}-60^{\circ} \mathrm{N}$ in December 1997. All gaps are filled by spatial extrapolation that does not appreciably influence the obtained results. Monthly $\Delta \mathrm{O}_{3} / \Delta t$ is simply the difference of total ozone values between months. Monthly mean ozone values are generally associated with ozone values near the middle of the month. Hence, for example, the January $\Delta \mathrm{O}_{3} / \Delta t$ here as a difference between January and December presents ozone changes from approximately 15 December to 15 January.

For the September-March period (1979-2002) we calculate daily meridional and vertical residual mean velocities $\left(\bar{v}^{*}, \bar{w}^{*}\right)$. The residual velocities are estimated from the quasi-geostrophic TEM thermodynamic and continuity equations:

$$
\begin{aligned}
& \frac{\partial \bar{T}}{\partial t}+\bar{v}^{*} \frac{1}{a} \frac{\partial \bar{T}}{\partial \varphi}+\bar{w}^{*} S=\bar{Q} \\
& \frac{1}{a \cos \varphi} \frac{\partial}{\partial \varphi}\left(\bar{v}^{*} \cos \varphi\right)+\frac{1}{\rho_{0}} \frac{\partial}{\partial z}\left(\rho_{0} \bar{w}^{*}\right)=0 .
\end{aligned}
$$

Here $\bar{T}$ is the zonal mean temperature; $\bar{Q}$ is the zonal mean net diabatic heating; $S=H N^{2} / R$ is the static stability parameter; the log-pressure vertical coordinate is $z=-$ $H \ln (p / 1000 \mathrm{hPa})$ with $H=7 \mathrm{~km}$; and $a, \varphi, R$ and $\rho_{0}$ are the radius of the Earth, latitude, the gas constant and a basic state density, respectively. Calculation of the residual circulation is an iteration procedure where at the first step we assume that $\bar{v}^{*}$ is equal to zero to get the first estimate of $\bar{w}^{*}$ from the thermodynamic Eq. (1). Then we get the first estimate of $\bar{v}^{*}$ at a given latitude from the continuity Eq. (2) through integration of the vertical derivative of $\rho_{0} \bar{w}^{*}$ from a pole to this latitude, assuming that $\bar{v}^{*}=0$ at the poles (for more details see e.g. Dunkerton, 1978; Solomon et al., 1986; Gille et al., 1987). The iteration procedure converges after two-three iterations.

Estimations of the residual circulation have large uncertainties mainly due to uncertainties in the calculated net heating rates (Eluszkiewicz et al., 1997). The usual consequence of these heating rate uncertainties is that the global mean mass balance is not maintained (the global integral of $\bar{w}^{*}$ on isobaric levels is not equal to zero). At each iteration, in order to reduce the global integral of $\bar{w}^{*}$ to zero, we apply a correction factor for $\bar{w}^{*}$ which is independent of latitude (e.g. Murgatroyd and Singelton, 1961; Shine, 1989). At an isobaric level such correction strongly influences accuracy of the estimated circulation in regions close to radiative equilibrium (small residual velocities). On average the correction is about $5-10 \%$ of uncorrected values of $\bar{w}^{*}$ in winter polar regions, $10-20 \%$ in the tropics and up to $30-50 \%$ in summer polar regions. Values of $10-20 \%$ in the tropics are similar to the $15 \%$ reported by Randel et al. (2002b). Large errors in 


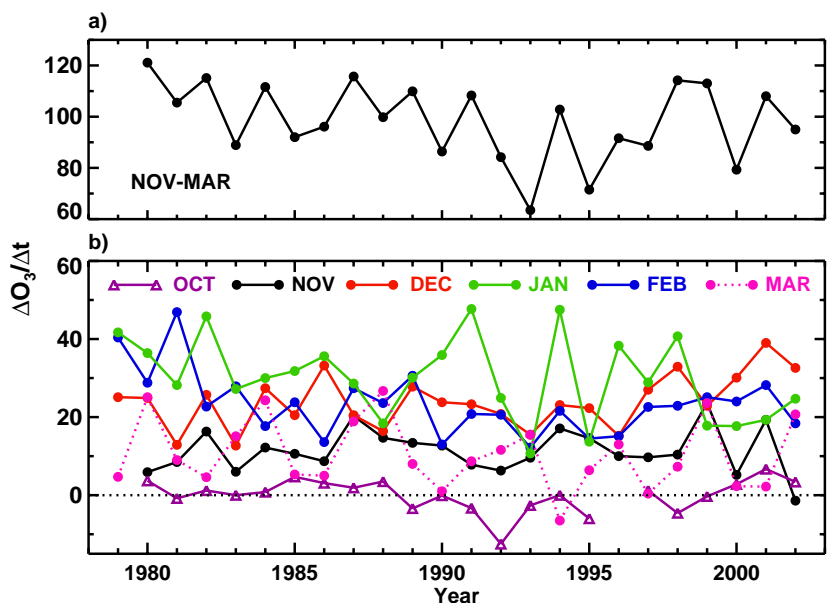

Fig. 1. Time series of zonal mean $\Delta \mathrm{O}_{3} / \Delta t$ averaged over $50^{\circ}-$ $60^{\circ} \mathrm{N}$ (a) for whole winter (November-March) and (b) for each month from October to March (DU/month).

the net heating rates and consequently in the estimated velocities also occur in regions closer to radiative equilibrium where the solar heating and the infrared cooling almost balance each other (Olaguer et al., 1992). The combination of initial "radiative" uncertainties and the following correction can result in larger uncertainties of the estimated $\bar{w}^{*}$ under conditions close to radiative equilibrium.

Since during the iterations we estimate $\bar{v}^{*}$ through integration of the vertical derivative of $\rho_{0} \bar{w}^{*}$, the calculated $\bar{v}^{*}$ accumulates uncertainties in the vertical derivative of $\rho_{0} \bar{w}^{*}$ from a pole to the given latitude for $\bar{v}^{*}$. Hence all uncertainties in $\bar{v}^{*}$ come non-locally from $\bar{w}^{*}$, and it is expected that $\bar{v}^{*}$ has larger uncertainties than $\bar{w}^{*}$. At the same time there is no method to estimate quantitative uncertainties in the diabatically-derived $\left(\bar{v}^{*}, \bar{w}^{*}\right)$ to define regions where we cannot depend on the calculated velocities. Only differences between the residual circulations obtained from different data sources can be examined (e.g. Eluszkiewicz et al., 1997). Hence the calculated residual circulation in the study is used as it is. We did not find any considerable difference in $\left(\bar{v}^{*}\right.$, $\bar{w}^{*}$ ) calculated on a daily basis and then averaged monthly with $\left(\bar{v}^{*}, \bar{w}^{*}\right)$ based on monthly averaged data.

Daily mean zonal mean $\mathrm{HF} \overline{v^{\prime} T^{\prime}}\left(v^{\prime}\right.$ is the eddy meridional wind and $T^{\prime}$ is the eddy temperature) is calculated for the same period as the residual velocities. Weighting with the cosine of the latitude is applied for averaging in latitudinal belts. Temperature, wind and net diabatic heating fields for calculations are taken from the ERA-40 reanalysis. Also, for comparison, we use temperature and wind data from the NCEP/NCAR reanalysis.
Table 1. Linear trends (DU/month decade) and confidence levels $(\%)$ in zonal mean $\Delta \mathrm{O}_{3} / \Delta t\left(50^{\circ}-60^{\circ} \mathrm{N}\right)$ during $1980-2002$.

\begin{tabular}{lcc}
\hline Season & Trend & Conf. level \\
\hline November & 0.3 & 11.8 \\
December & 4.5 & 94.5 \\
January & -4.9 & 86.1 \\
February & -3.6 & 86.8 \\
March & -3.0 & 69.3 \\
Nov.-Dec. & 4.8 & 91.0 \\
Jan.-Feb. & -8.5 & 96.6 \\
Jan.-March & -11.5 & 99.4 \\
Nov.-March & -6.7 & 83.5 \\
\hline
\end{tabular}

The confidence levels are estimated with use of the Student's $t$-test.

\section{Ozone tendencies}

Figure 1 shows the total wintertime (November-March, Fig. 1a) and monthly mean (from October to March, Fig. 1b) zonal mean $\Delta \mathrm{O}_{3} / \Delta t$ averaged over $50^{\circ}-60^{\circ} \mathrm{N}$. The year for the winter denotes the year as in January. The TOMS/SBUV merged ozone dataset begins in November 1978 so there is no $\Delta \mathrm{O}_{3} / \Delta t$ in October and November of the 1979 winter. Also there is a data gap in October of the 1996 winter. The tendencies are always negative in September (not shown) and close to zero in October which presents a transition period between summer photochemical decay and wintertime dynamical buildup. On average the tendencies increase until January when they reach a seasonal maximum and then decrease towards spring becoming negative in April (not shown). The December and February values are of about the same magnitude. However, in some years seasonal behaviour of $\Delta \mathrm{O}_{3} / \Delta t$ differs strongly from the average, reflecting the influence of various random dynamical and chemical processes on midlatitude ozone during winter. Monthly ozone tendencies do not correlate with each other and can be regarded as independent time series. In contrast, monthly total ozone has strong autocorrelations (Fioletov and Shepherd, 2003). Only the January and February tendencies correlate significantly $(r=0.52$ and 0.48$)$ with the total wintertime $\Delta \mathrm{O}_{3} / \Delta t$. Indeed, low January $\Delta \mathrm{O}_{3} / \Delta t$ in 1993 and 1995 (high in 1982, 1991 and 1994) result in low (high) total wintertime $\Delta \mathrm{O}_{3} / \Delta t$ in those years. A combination of low $\Delta \mathrm{O}_{3} / \Delta t$ in November, January and March of 2000 also leads to low wintertime $\Delta \mathrm{O}_{3} / \Delta t$ even though $\Delta \mathrm{O}_{3} / \Delta t$ is quite high in December and February. Thus, low $\Delta \mathrm{O}_{3} / \Delta t$ at the end of winter does not necessarily mean less poleward ozone transport or more chemical loss through the whole winter.

Estimated linear trends in $\Delta \mathrm{O}_{3} / \Delta t$ for the 1980-2002 period are presented in Table 1. Though no significant trends are found for any month, it is interesting to note that the sign of the trend changes from positive in November (about zero) and December to negative from January to March. Such 

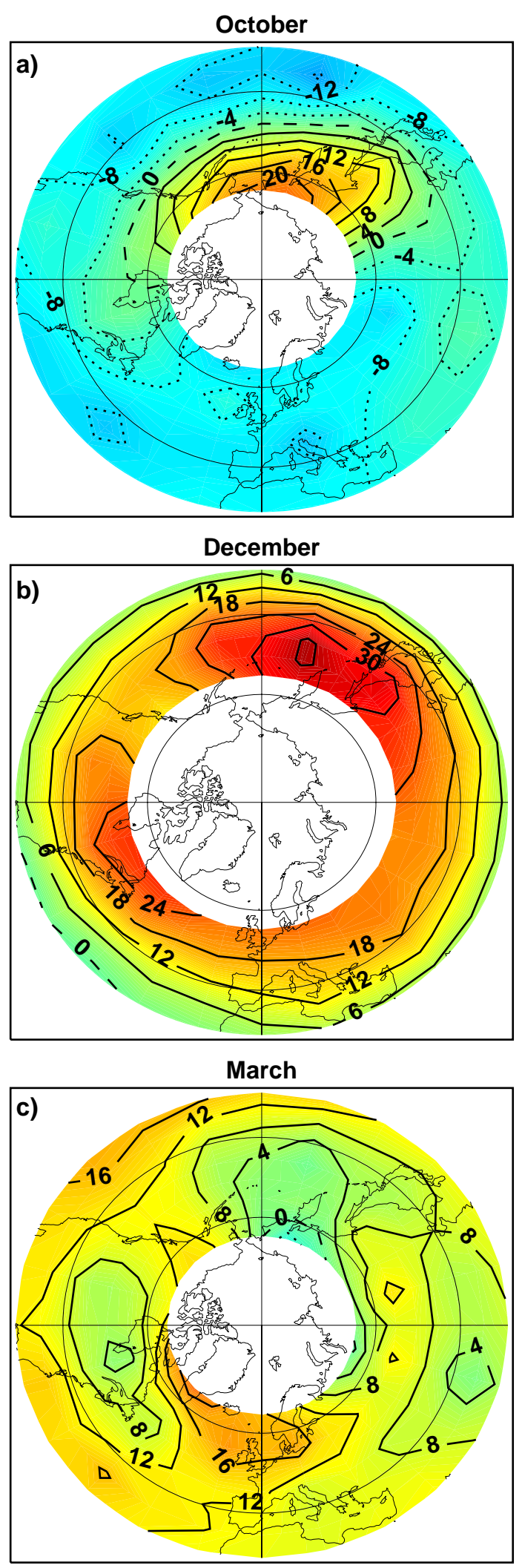

Fig. 2. $\Delta \mathrm{O}_{3} / \Delta t$ (DU/month) in (a) October, (b) December and (c) March, averaged for 1980-2002. Contour interval is $4 \mathrm{DU} / \mathrm{month}$ for (a) and (c), and 6 DU/month for (b).
$\Delta \mathrm{O}_{3} / \Delta t$ trend distribution is similar to the HF trends in November-February shown by Randel et al. (2002a): weak insignificant positive trends in November, December and negative ones in January (at the edge of statistical significance) and February (insignificant) for 1979-2000. Newman and Nash (2000) found significant negative trends in the January-February averaged HF (1979-1999). Later Karpetchko and Nikulin (2004) confirmed significant negative trends in the January-February HF and positive trends in the November-December HF which are at the edge of statistical significance (1979-2002). Averaged in the same way $\Delta \mathrm{O}_{3} / \Delta t$ shows a similar picture: an insignificant positive trend for November-December as well as a significant negative trend for January-February. The negative trend becomes stronger and more significant for January-March (see Table 1) while the total wintertime trend is still negative but insignificant because of the positive trend in NovemberDecember. Hence the decline in $\Delta \mathrm{O}_{3} / \Delta t$ occurs only during January-March. We use the 1980-2002 period to be consistent in all months since there is no data in November 1979. If, for example, we include 1979, the January and February trends become more negative as can be seen from Fig. $1 \mathrm{~b}$.

Figure 2 shows $\Delta \mathrm{O}_{3} / \Delta t$ over the $\mathrm{NH}$ averaged for 1980 2002 in the initial (October), middle (December) and final (March) stages of the ozone buildup. Though the October zonal mean $\Delta \mathrm{O}_{3} / \Delta t$ is about zero (Fig. 1b), a longitudinal distribution of tendencies in October is not uniform (Fig. 2a). A positive maximum is located over the north-eastern edge of Russia while the opposite part of the $\mathrm{NH}$ is covered by negative values. It is interesting to note that a subtropical minimum of $\Delta \mathrm{O}_{3} / \Delta t$ is located over the Pacific just south of the positive maximum. Presence of the north-south dipole suggests intensification of northward ozone transport which is confined within the Pacific region. Also, deepening of the Aleutian low (from summer to winter) and associated decreasing of the tropopause height can result in accumulation of ozone in the lower stratosphere. In November (not shown) the positive maximum of $\Delta \mathrm{O}_{3} / \Delta t$ is still centred over the north-eastern edge of Russia and positive tendencies spread eastward and westward from the maximum covering almost the whole region north of $30^{\circ} \mathrm{N}$ with the exception of a negative region over the Atlantic. The December $\Delta \mathrm{O}_{3} / \Delta t$ (Fig. $2 \mathrm{~b}$ ) is positive over all $\mathrm{NH}$ midlatitudes and the second positive maximum which can be associated with the Icelandic low appears over the north-western Atlantic. The same structure with greater magnitude is seen in January (not shown). The February (not shown) and March (Fig. 2c) tendencies have less resemblance to the DecemberJanuary ones especially in March when the $\Delta \mathrm{O}_{3} / \Delta t$ pattern has smaller scale features and differs strongly from other months.

The longitude distribution of $\Delta \mathrm{O}_{3} / \Delta t$ in October-January is similar to total ozone distribution in the same months which is related to a structure of quasi-stationary planetary waves in the lower stratosphere (Kurzeja, 1984; Hood and 

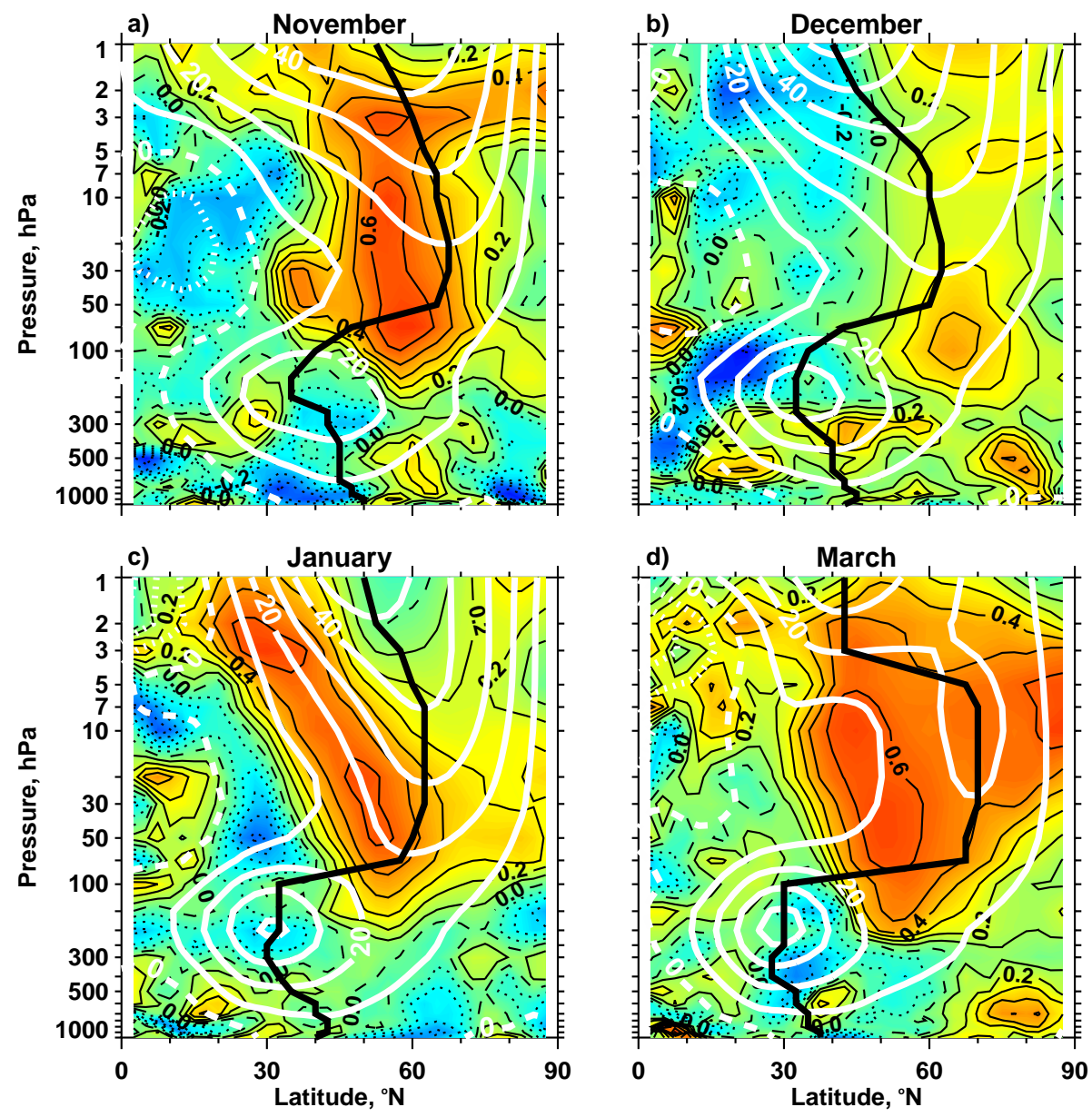

Fig. 3. Correlation between $\Delta \mathrm{O}_{3} / \Delta t\left(50^{\circ}-60^{\circ} \mathrm{N}\right)$ and $\mathrm{HF}$ (colours and black contours) in (a) November, (b) December, (c) January and (d) March. HF is averaged from 15 th of previous month to 15 th of given month. White contours represent zonal mean zonal wind averaged for 1980-2002 (interval $10 \mathrm{~m} \mathrm{~s}^{-1}$ ) and thick black line is the maximum wind at each level. Positive contour values are solid, negative values are dotted and zero contours are dashed. The $95 \%$ and $99 \%$ confidence levels (Student's $t$-test) are 0.41 and 0.53 , respectively.

Zaff, 1995). These waves still exist in the lower stratosphere during the February-March period that is also mirrored in total ozone fields (not shown) but the $\Delta \mathrm{O}_{3} / \Delta t$ patterns are not well tied to the wave structure as in the preceding months. The less pronounced planetary wave pattern in $\Delta \mathrm{O}_{3} / \Delta t$ during February and March is most probably a result of chemical ozone loss inside the polar vortex and following export of the vortex air into midlatitudes. These processes are more intensive in late winter and early spring (Hadjinicolaou and Pyle, 2004) and can introduce strong spatial deviations in the midlatitude $\Delta \mathrm{O}_{3} / \Delta t$ fields, especially during the vortex breakup. For the period studied, 1980-2002, the vortex breakup at the $475 \mathrm{~K}$ level [defined as the date when the maximum wind speed averaged around the vortex edge drops below $15.2 \mathrm{~m} / \mathrm{s}$, following the method of Nash et al. (1996)] occurred seven times in March (14 times in April and twice in May) (Karpechko et al., 2005). As a summary of the chapter we conclude that the wintertime ozone buildup begins over the north-eastern edge of Russia in October, spreads over the
$\mathrm{NH}$ in November and finally covers all $\mathrm{NH}$ midlatitudes in December. In October-January total ozone is more under dynamical control and the longitude structure of $\Delta \mathrm{O}_{3} / \Delta t$ mirrors the longitude structure of planetary waves in the lower stratosphere. Chemistry begins to play a more significant role in the late winter-early spring when the $\Delta \mathrm{O}_{3} / \Delta t$ fields show less similarity with the planetary wave pattern.

\section{Heat flux and ozone tendencies}

Figure 3 shows one-point correlations of $\Delta \mathrm{O}_{3} / \Delta t$ averaged over $50^{\circ}-60^{\circ} \mathrm{N}$ with $\mathrm{HF}$ for $(\mathrm{a}-\mathrm{c})$ November-January and (d) March. For these plots, daily values of $\mathrm{HF}$ are averaged over one-month periods consistent with monthly mean $\Delta \mathrm{O}_{3} / \Delta t$ (15th of previous month-15th of given month). For example the January HF means here an average from 15 December to 15 January. In November (Fig. 3a) an area of pronounced positive correlations $\left(r_{\max }=0.69\right)$ is located in the midlatitude 
stratosphere with a maximum stretching from 100 to $10 \mathrm{hPa}$. The positive correlations in December are weak and insignificant in most of the stratosphere north of $50^{\circ} \mathrm{N}$ (Fig. 3b). A small region in the lower stratosphere is on the edge of statistical significance $\left(r_{\max }=0.45\right)$. Also, there are significant negative correlations in the tropical upper troposphere. This feature is absent in other months and looks random so we do not discuss it in the paper. In January (Fig. 3c) positive correlations $\left(r_{\max }=0.68\right)$ cover all heights in the stratosphere with a slope from the upper subtropical to the lower midlatitude stratosphere. The February correlations north of $50^{\circ} \mathrm{N}$ (not shown) are qualitatively almost identical to the December ones (Fig. 3b) but the lower stratospheric maximum is clearly pronounced $\left(r_{\max }=0.69,70 \mathrm{hPa}, 70^{\circ} \mathrm{N}\right)$. In March (Fig. 3d) positive correlations $\left(r_{\max }=0.71\right)$ spread over all extratropical stratosphere reaching the North Pole. The correlation pattern between the wintertime $\Delta \mathrm{O}_{3} / \Delta t$ and $\mathrm{HF}$ for the same period (not shown) is similar to the December and February ones. The maximum correlation coefficient is about 0.7 , located at $70 \mathrm{hPa}, 65^{\circ} \mathrm{N}$.

There are no significant correlations between the zonal mean $\Delta \mathrm{O}_{3} / \Delta t$ and $\mathrm{HF}$ in October when the zonal mean $\Delta \mathrm{O}_{3} / \Delta t$ is about zero. However, if we average $\Delta \mathrm{O}_{3} / \Delta t$ over the region with maximum positive values in Fig. 2a $\left(60^{\circ}-70^{\circ} \mathrm{N}, 105^{\circ}-225^{\circ} \mathrm{E}\right.$; the North Pacific hereafter), positive correlations $\left(r_{\max }=0.7\right)$ centred at $55^{\circ}-60^{\circ} \mathrm{N}$ appear in the stratosphere (not shown). The pattern obtained is absolutely identical to the November one for the zonal mean $\Delta \mathrm{O}_{3} / \Delta t$ in Fig. 3a. Though the North Pacific $\Delta \mathrm{O}_{3} / \Delta t$ is not a zonal mean quantity, the strong correlation can be explained by the fact that the considerable contribution to the October zonal mean HF also comes from the Pacific. Zonal mean HF between $50^{\circ} \mathrm{N}$ and $70^{\circ} \mathrm{N}$ (the region with maximum correlations in Fig. 3a) shows significant coherence $(r=0.75 \div 0.85)$ with the Pacific HF $\left(50^{\circ}-70^{\circ} \mathrm{N}, 105^{\circ}-\right.$ $225^{\circ} \mathrm{E}$ ) at all levels in the stratosphere. This finding supports the idea that northward ozone transport strengthens over the Pacific already in October. We should note that the latitude belt $60^{\circ}-70^{\circ} \mathrm{N}$ is different from other months. The October $\Delta \mathrm{O}_{3} / \Delta t$ averaged over $50-60^{\circ} \mathrm{N}$ and the same longitudes $\left(105^{\circ}-225^{\circ} \mathrm{E}\right)$ shows only weak insignificant positive correlations with HF in the stratosphere.

Presence of positive correlations between $\Delta \mathrm{O}_{3} / \Delta t$ and $\mathrm{HF}$ is in agreement with theoretical considerations and previous results (e.g. Randel et al., 2002a; Salby and Callaghan, 2002; Weber et al., 2003). However the correlation patterns are not uniform throughout winter: they are identical in October and November during the formation of the polar vortex but not as homogeneous as in the following months with a developed or dissipated polar vortex. One reviewer noted that the strongest positive correlations in Fig. 3 roughly follow the location of the edge of the polar vortex. On Fig. 3 we superimposed zonal mean zonal wind (averaged for 1980-2002 and for respective months) whose maximum values in the extratropical stratosphere can approximately represent the edge of the polar vortex. The strongest correlations are located equatorward of the vortex edge in October (not shown), November (Fig. 3a) and January (Fig. 3c), but poleward of the vortex edge in December (Fig. 3b) and February (not shown). A remarkable difference between these two cases is that strong correlations persist up to $3 \mathrm{hPa}$ in the equatorward position while they are limited to the lower stratosphere in the poleward position. Such distribution of the high correlation patterns may be related to the existence of the polar and midlatitude waveguides located poleward and equatorward of the polar night jet respectively (e.g. Dickinson, 1968). Depending on the presence of one of the waveguides, upward propagating waves from the troposphere can be refracted either to the midlatitude stratosphere or to the polar stratosphere while the existence and position of both waveguides are defined by the height-latitude structure of zonal wind. In March (Fig. 3d) when the polar vortex weakens or breaks up maxima of correlations are observed on both sides of the polar night jet, suggesting the existence of the polar and midlatitude waveguides at the same time. Hence the location of the strongest correlations between $\Delta \mathrm{O}_{3} / \Delta t$ and HF may depend on the height-latitude structure of zonal wind which defines whether the polar or midlatitude waveguide exists (or both together as in March).

Maximum values of correlations are often located above $100 \mathrm{hPa}$ and at different latitudes. The region $45^{\circ}-75^{\circ} \mathrm{N}$, $100 \mathrm{hPa}$ is usually taken to define approximately the amount of wave activity entering into the stratosphere from the troposphere. As can be seen from Fig. 3, the HF averaged over this region is not always an optimum proxy of wave forcing for the regression models describing midlatitude total ozone. $\Delta \mathrm{O}_{3} / \Delta t$ has a pronounced relation with HF in the early stage of ozone buildup (October-November), although in October this relation is regional. It is not clear why correlations are weaker in the middle stage of the buildup (December) in comparison with the preceding and following months. Qualitatively the December correlation pattern is similar to the February one when correlations are strong. The November $\Delta \mathrm{O}_{3} / \Delta t$ is lower than the December $\Delta \mathrm{O}_{3} / \Delta t$ but shows the pronounced positive correlation with HF in the stratosphere. The extrapolation of the missing December data in 1992-1994 and 1997-1998 can have influenced the results obtained, but removing these 5 years does not change the December correlations. Consistent results are obtained using the NCEP/NCAR reanalysis (limited by the uppermost $10 \mathrm{hPa}$ level) so both the ERA40 and NCEP/NCAR data sets are in agreement here. In general, maximum absolute values of correlation coefficients during winter are close to 0.7 (with the exception of December) thus HF explains about $50 \%$ of variance in $\Delta \mathrm{O}_{3} / \Delta t$.

Randel et al. (2002) mention that one source of variability in the results is random episodic nature of wave forcing with the usual wave event duration being about 1-2 weeks. Hence the obtained correlation coefficients also depend on which part of individual wave events have fallen into an averaging 

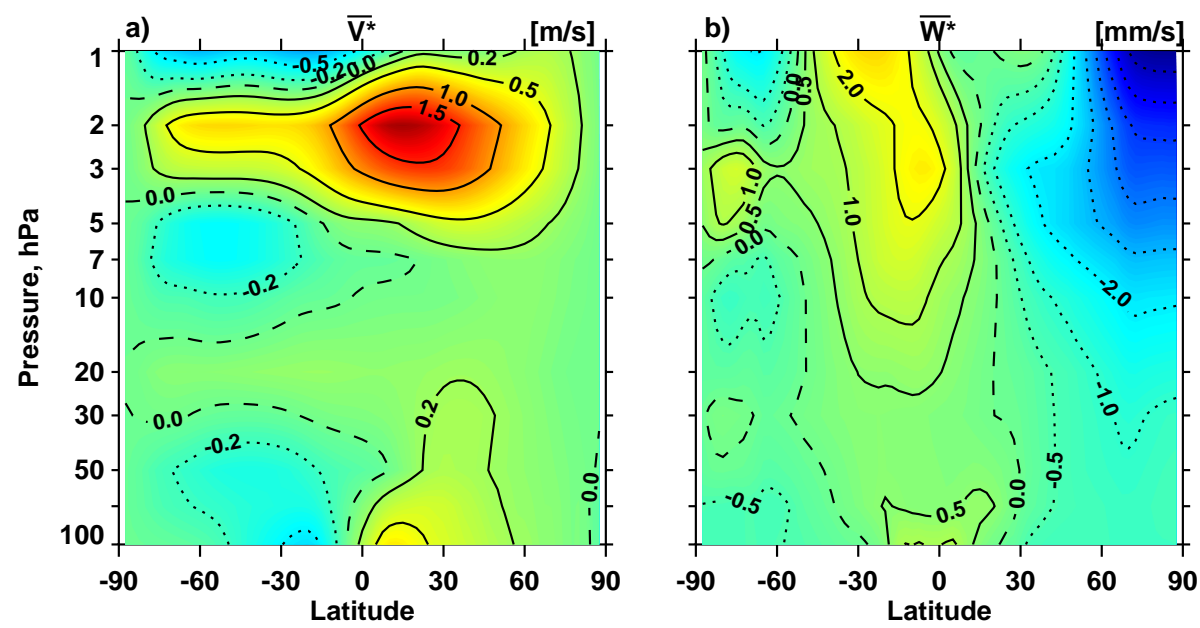

Fig. 4. The January (a) $\bar{v}^{*}$ and (b) $\bar{w}^{*}$ averaged for 1980-2002. Contours are: $0, \pm 0.2, \pm 0.5, \pm 1.0, \pm 1.5 \mathrm{~m} \mathrm{~s}^{-1}$ for (a), and $0, \pm 0.5, \pm 1.0$, later increased by $1.0 \mathrm{~mm} \mathrm{~s}^{-1}$ for (b).

period for HF from year to year. Practically, in each month (not in December) we can select an averaging period (plusminus several days) which gives higher maximum correlation coefficients (more than 0.7). However, this "optimum" period is different from month to month so in the study we use the same period giving more or less consistent results for all winter months.

\section{Heat fluxes and the residual circulation}

It is widely recognized that HF should correlate with the strength of the residual circulation: stronger wave forcing results in stronger residual circulation and vice versa. The expected response to wave forcing was found in temperature, zonal wind and ozone (e.g. Newman et al., 2001; Salby and Callaghan, 2002). Ma et al. (2004) showed a close correlation between $\mathrm{HF}$ and $\bar{w}^{*}$ in the model results. Nevertheless, before examining the relationship between the residual circulation and $\Delta \mathrm{O}_{3} / \Delta t$, we should verify how well $\mathrm{HF}$ is correlated with the diabatically-derived residual circulation during winter.

An example of the January $\bar{v}^{*}$ and $\bar{w}^{*}$ averaged for 1980 2002 is shown in Fig. 4. Qualitatively the global patterns of $\bar{v}^{*}$ and $\bar{w}^{*}$ agree with previous studies (e.g. Solomon et al., 1986; Eluszkiewicz et al., 1997). Upward motions in the tropics shifting to the summer hemisphere with altitude and poleward-downward motions in the winter extratropics are the prominent features of the residual circulation. A layered circulation south of $60^{\circ} \mathrm{S}$ may be due both to the vertical oscillations in the ERA-40 temperature at high latitudes of the SH (SPARC 2002) and to larger uncertainties in the calculated residual velocities during the SH summer. The summer stratosphere, especially the lower, is much closer to radiative equilibrium than its winter counterpart (e.g. Shine,
1987), leading to smaller values for the calculated velocities as well to larger uncertainties. The layered circulation is not observed for example in September when the SH stratosphere is not as close to radiative equilibrium as in January. Absolute values of $\bar{w}^{*}$ are less than $1 \mathrm{~mm} \mathrm{~s}^{-1}$ in the lower stratosphere and increase up to $8 \mathrm{~mm} \mathrm{~s}^{-1}$ in the upper polar stratosphere. $\bar{v}^{*}$ has its maximum in the upper tropical stratosphere (about $2 \mathrm{~m} \mathrm{~s}^{-1}$ ) and values less than $0.5 \mathrm{~m} \mathrm{~s}^{-1}$ below $5 \mathrm{hPa}$. A small region with higher $\bar{v}^{*}$ and $\bar{w}^{*}$ between 100 and $50 \mathrm{hPa}$ centred at the equator is an exception that most likely represents an influence of the tropical convection. In this study we concentrate on the $\mathrm{NH}$ and limit our study of the residual circulation to the region between $30^{\circ} \mathrm{S}$ and $90^{\circ} \mathrm{N}$.

Figure 5 shows one-point correlations of HF averaged over $45^{\circ}-75^{\circ} \mathrm{N}, 100 \mathrm{hPa}$ with $\bar{w}^{*}$ for (a) November and (b) January. Daily values of the residual velocities and HF are averaged over one-month periods in the same way as in the previous section (15th of previous month-15th of given month). An area of strong negative correlations north of $60^{\circ} \mathrm{N}$ appears in all months from November to March. December, February and March are identical to January and not shown here. Negative correlations are confined to the lower stratosphere in November $\left(r_{\min }=-0.72\right)$ and spread up to $2-3 \mathrm{hPa}$ in the following months $\left(r_{\min } \approx-0.8 \div-0.9\right)$. Positive correlations with upward motions exist in the tropical stratosphere but they are nonuniform and only some patches are significant in December-March. The obtained correlations are not sensitive to a choice of level for HF in the lower stratosphere. However, if $\mathrm{HF}$ is taken at levels higher than $20 \mathrm{hPa}$, the polar minimum shifts upward and the tropical positive correlations become more homogeneous above $10 \mathrm{hPa}$. Newman et al. (2001) showed that correlation of HF and the polar stratospheric temperature depends on radiative damping time which is shorter in the middle and upper stratosphere and 

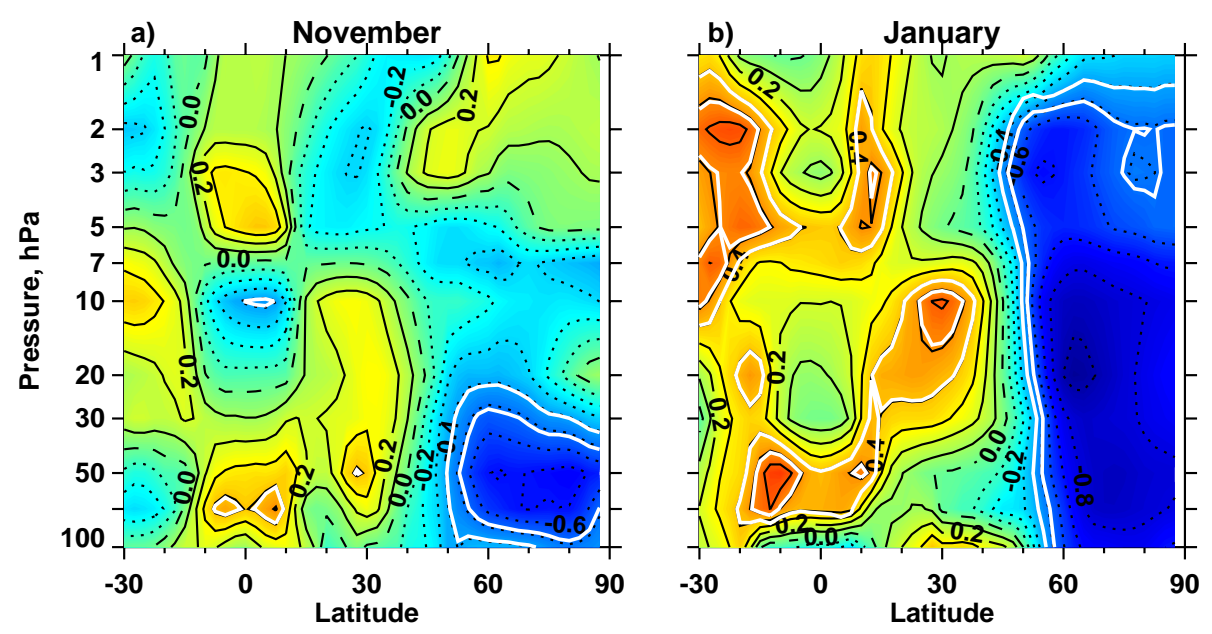

Fig. 5. Correlation between $\mathrm{HF}\left(45^{\circ}-75^{\circ} \mathrm{N}, 100 \mathrm{hPa}\right)$ and $\bar{w}^{*}$ in (a) November and (b) January. HF and $\bar{w}^{*}$ are averaged from 15 th of previous month to 15 th of given month. Positive contour values are solid, negative values are dotted and zero contours are dashed. Contour interval is 0.1 . The first and second white lines are the $95 \%$ and $99 \%$ confidence levels.
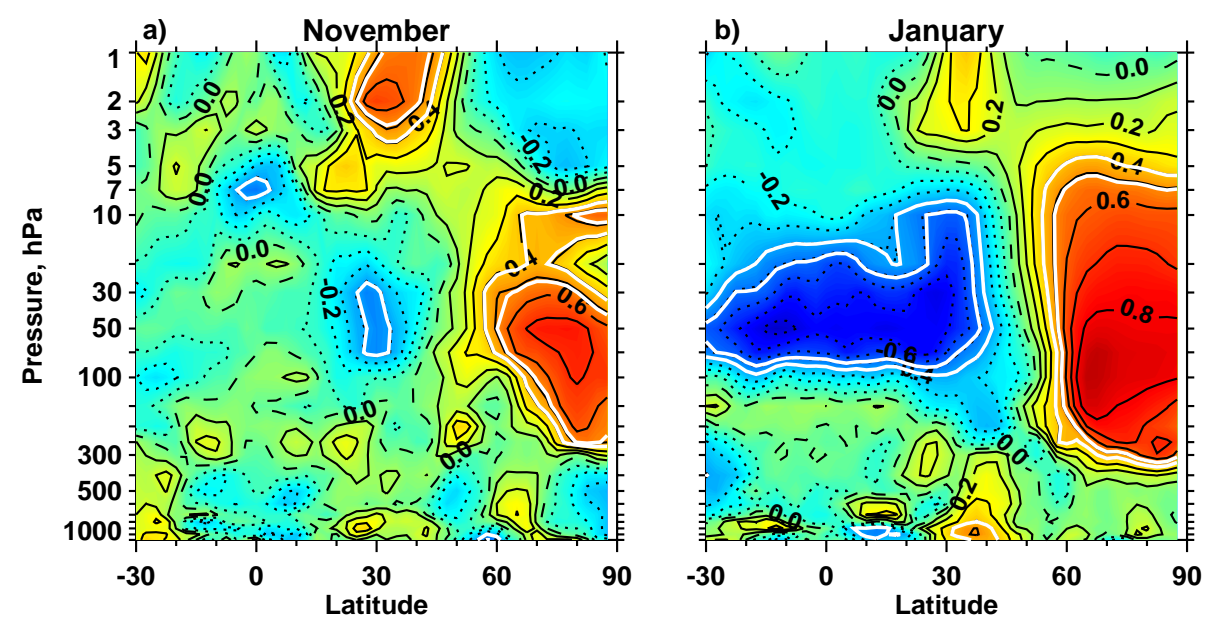

Fig. 6. Correlation between $\mathrm{HF}\left(45^{\circ}-75^{\circ} \mathrm{N}, 100 \mathrm{hPa}\right)$ and $\Delta T / \Delta t$ in (a) November and (b) January. HF and $\Delta T / \Delta t$ are averaged from 15 th of previous month to 15 th of given month. Contours and shading as in Fig. 5.

longer in the lower stratosphere (Newman and Rosenfield, 1997). One-month periods as used here can mask part of the variability in regions with shorter damping time than one month. Indeed, $\mathrm{HF}$ taken at $10-5 \mathrm{hPa}$ and 10 -day averaging for both $\mathrm{HF}$ and $\bar{w}^{*}$ bring pronounced positive correlation $\left(r_{\max } \approx 0.7 \div 0.9\right)$ between $30^{\circ} \mathrm{S}-30^{\circ} \mathrm{N}$ above $10 \mathrm{hPa}$. However, because of the shorter period, variability in the 10day correlation patterns is higher than in the monthly samples. The fragmented correlation pattern in the lower tropical stratosphere for monthly samples lets us assume that interannual variability of $\bar{w}^{*}$ is not well captured over the region because of larger uncertainties. We can test this suggestion by using temperature tendency $(\Delta T / \Delta t)$ which operates coherently with HF over the entire winter hemisphere and even over the subtropics of the summer hemisphere (Randel, 1993; Salby and Callaghan, 2002). Figure 6 shows correla- tions of HF with $\Delta T / \Delta t$ for November and January by analogy with Fig. 5. A clear pronounced north-south dipole like in January (Fig. 6b) is observed from December to March. Negative correlations $\left(r_{\min } \approx-0.7 \div-0.9\right)$ cover the whole lower stratosphere in the tropics and subtropics of both hemispheres. In November (Fig. 6a) only weak negative correlations at the edge of significance exist in the $\mathrm{NH}$ subtropics but positive ones $\left(r_{\max }=0.74\right)$ are located in the polar lower stratosphere/upper troposphere. The $\Delta T / \Delta t$ correlation patterns also depend on radiative damping time and show similar behaviour to $\bar{w}^{*}$, moving upward with a 10-day averaging period and HF taken at 10-5 hPa. The strong correlation between $\mathrm{HF}$ and $\Delta T / \Delta t$ in the tropical lower stratosphere supports the presence of larger uncertainties in $\bar{w}^{*}$ over this region. In fact, the tropical lower stratosphere is close to radiative equilibrium because the dynamical temperature response 

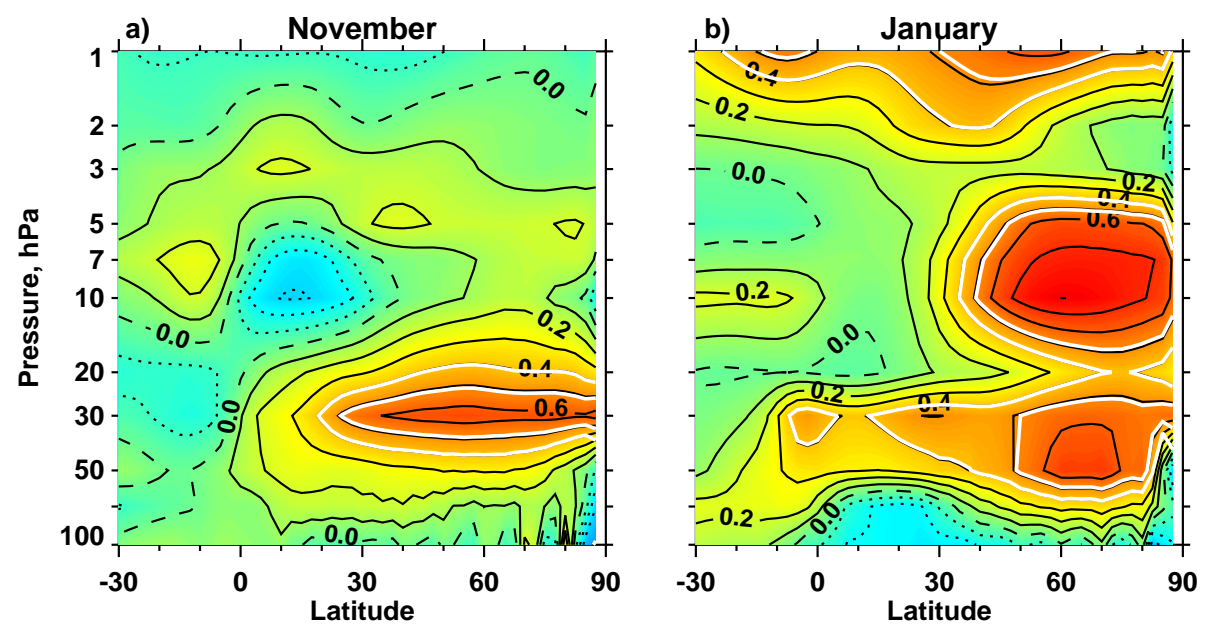

Fig. 7. As Fig. 5 but for $\bar{v}^{*}$.

to extratropical wave forcing is much smaller (only several Kelvins) in the tropics as compared with the extratropics (Randel, 1993; Salby and Callaghan, 2002). The correction applied to the velocities during calculations, as mentioned in Sect. 2, is about $10-20 \%$ of the uncorrected values of $\bar{w}^{*}$ in the tropics, i.e. two times greater than for the NH high latitudes. It is most likely that for the tropical lower stratosphere, the combination of small net heating rates and the correction procedure leads to large uncertainties in $\bar{w}^{*}$.

As expected, HF correlates positively with $\bar{v}^{*}$ in the extratropical stratosphere in all months from November to March. In November (Fig. 7a) an area of positive correlations $\left(r_{\max }=0.65\right)$ is narrow and elongated from the Equator to the North Pole along the $30 \mathrm{hPa}$ level. During December-March the extratropical correlation patterns below $3 \mathrm{hPa}$ are nearly analogous to the January pattern (Fig. 7b). Positive correlations extend upward and the maximum $\left(r_{\max } \approx 0.7-0.8\right)$ is located in the polar middle stratosphere north of $60^{\circ} \mathrm{N}$. At the same time the positive correlations for $\bar{v}^{*}$ are not as uniform during winter as the negative correlations for $\bar{w}^{*}$.

In October when only $\Delta \mathrm{O}_{3} / \Delta t$ averaged over the North Pacific is coupled with HF, no significant correlations were found between $\mathrm{HF}\left(45^{\circ}-75^{\circ} \mathrm{N}, 100 \mathrm{hPa}\right)$ and either $\bar{w}^{*}$ nor $\bar{v}^{*}$. However, HF taken above $30 \mathrm{hPa}$ correlates well $(|\mathrm{r}| \approx 0.7-0.8)$ with both $\bar{w}^{*}$ and $\bar{v}^{*}$ in the middle stratosphere north of $60^{\circ} \mathrm{N}$. Also HF shows good coherence with $\Delta T / \Delta t$ $\left(r_{\max } \approx 0.7\right)$ in the polar lower stratosphere that is similar to November (Fig. 6a). As for HF, the main contribution to interannual variability of zonal mean $\Delta T / \Delta t$ in October comes from the Pacific. Hence all relations between zonal mean quantities in October mainly mirror local processes over the Pacific.

The above results demonstrate that during winter there is a good agreement with the expected response of the diabatically-derived residual circulation to wave forcing in the middle and upper tropical stratosphere as well as in the polar winter stratosphere. However, the residual circulation in the lower tropical stratosphere which is close to radiative equilibrium shows a weak relation with the wave forcing because of larger uncertainties. At the same time interannual variations of $\Delta T / \Delta t$ have much better coherence with $\mathrm{HF}$ in regions close to radiative equilibrium than the estimated residual velocities. HF, $\Delta T / \Delta t$ and the residual circulation based on the NCEP/NCAR reanalysis (only heating rates from the ERA-40) give consistent results at levels available in both datasets.

\section{The residual circulation and ozone tendencies}

Finally we examine how $\Delta \mathrm{O}_{3} / \Delta t$ is related to the estimated residual circulation and which of vertical or horizontal advections by the residual circulation to be preferred for describing interannual variability in $\Delta \mathrm{O}_{3} / \Delta t$. Here we use time averaging for $\bar{w}^{*}$ and $\bar{v}^{*}$ from 20th of previous month to 20th of given month that results in approximately equal maximum absolute values of correlation coefficients in all months. Figure 8 shows one-point correlations of $\Delta \mathrm{O}_{3} / \Delta t$ averaged over $50^{\circ}-60^{\circ} \mathrm{N}$ with $\bar{w}^{*}$ for $(a-c)$ November-January and (d) March. Midlatitude correlation patterns are similar in November-February (February not shown): an area of negative correlations is located in the lower stratosphere and centred at $50^{\circ}-60^{\circ} \mathrm{N}, 50-70 \mathrm{hPa}$ $\left(r_{\min } \approx-0.65 \div-0.75\right)$. The spatial structure of extratropical correlations is more uniform from month to month in comparison with HF (Fig. 3). Noticeable correlation is observed in December (Fig. 8b) when correlation between $\Delta \mathrm{O}_{3} / \Delta t$ and HF is weak (Fig. 3b). In March (Fig. 8d) negative correlations spread upward and northward covering almost the whole extratropical stratosphere. The observed negative correlations in the extratropics are consistent with the expected response in $\Delta \mathrm{O}_{3} / \Delta t$ : stronger downward advection brings 

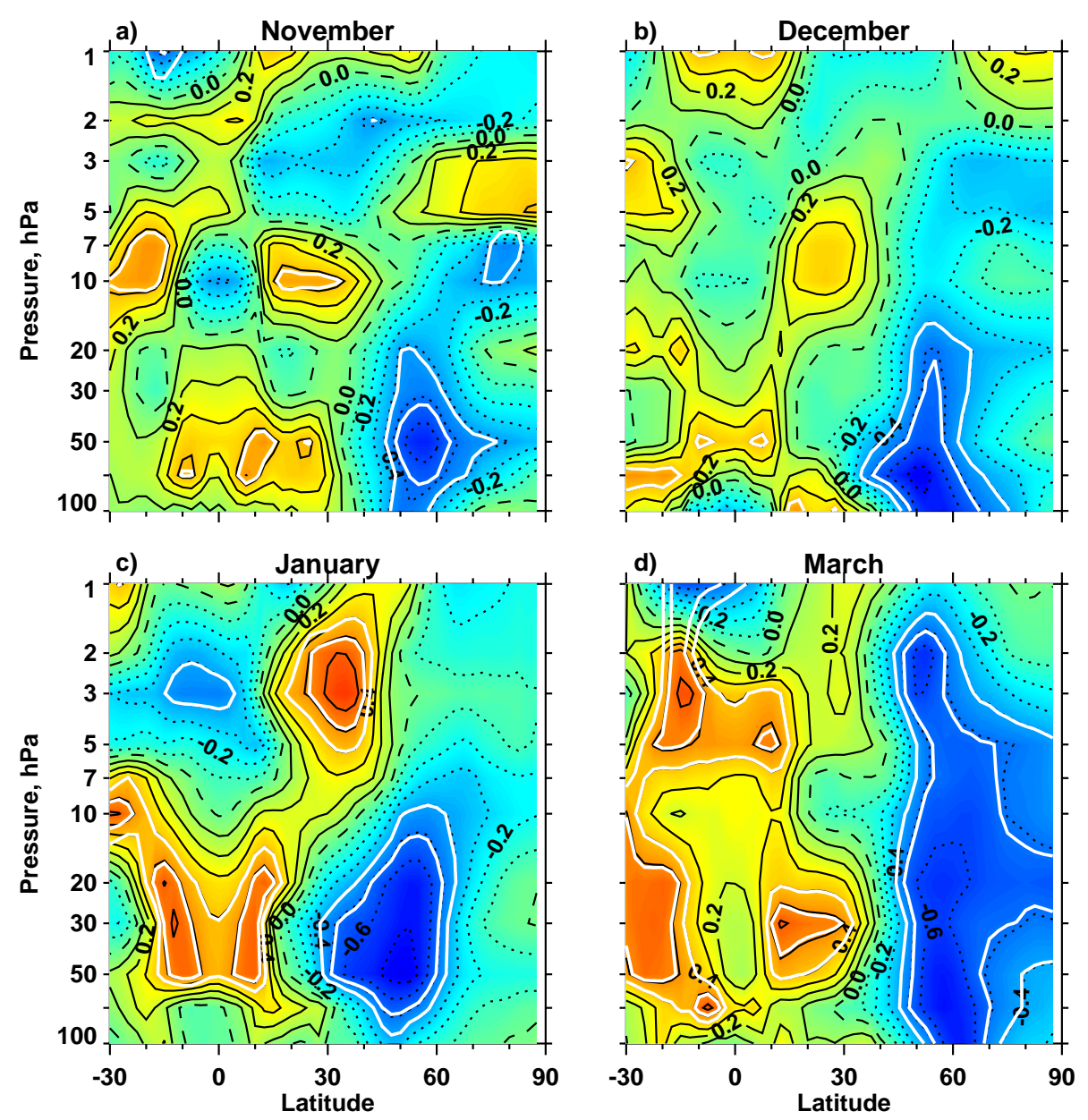

Fig. 8. Correlation between $\Delta \mathrm{O}_{3} / \Delta t\left(50^{\circ}-60^{\circ} \mathrm{N}\right)$ and $\bar{w}^{*}$ in (a) November, (b) December, (c) January and (d) March. $\bar{w}^{*}$ is averaged from 20th of previous month to 20th of given month. Contours and shading as in Fig. 5.

more ozone into the lower stratosphere where ozone has a long photochemical lifetime (Brasseur and Solomon, 1986), resulting in ozone accumulation. Positive correlations in the tropics are also in agreement with theory since stronger tropical upwelling is related to stronger extratropical downwelling. However, positive correlations in the tropics are variable and more marked in January and March but weaker in other months. Such heterogeneity may be explained by larger uncertainties in $\bar{w}^{*}$ over the tropics compared to the extratropics (see Sect. 2). Maximum absolute values of correlation coefficients $(\approx 0.7)$ and accordingly explained variance $(\approx 50 \%)$ are the same as for HF. Changing the averaging period for $\bar{w}^{*}$ for several days can also give higher absolute correlation coefficients in separate months that is similar to the behaviour of the HF correlations.

The maximum response of $\bar{w}^{*}$ to wave forcing is observed north of $60^{\circ} \mathrm{N}$ (Fig. 5), but the strongest negative correlations between $\Delta \mathrm{O}_{3} / \Delta t$ and $\bar{w}^{*}$ are found south of $60^{\circ} \mathrm{N}$ where the correlation between $\bar{w}^{*}$ and $\mathrm{HF}\left(45^{\circ}-75^{\circ} \mathrm{N}, 100 \mathrm{hPa}\right)$ is weak. As noted in Sect. 4 , the region $45^{\circ}-75^{\circ} \mathrm{N}, 100 \mathrm{hPa}$ does not always coincide with a region of the strongest correlations between $\Delta \mathrm{O}_{3} / \Delta t$ and $\mathrm{HF}$ (Fig. 3). Indeed, HF averaged over the regions with strongest correlation in separate months (Fig. 3) shows almost the same correlation patterns with $\bar{w}^{*}$ as $\Delta \mathrm{O}_{3} / \Delta t$ in Fig. 8. Hence, HF averaged over $45^{\circ}-75^{\circ} \mathrm{N}, 100 \mathrm{hPa}$ describes the residual circulation in high latitudes well but not in midlatitudes.

Theoretically extratropical $\Delta \mathrm{O}_{3} / \Delta t$ correlates positively with the northward mean meridional transport in the stratosphere. Though there are expected positive correlations between $\Delta \mathrm{O}_{3} / \Delta t$ and $\bar{v}^{*}$ in all months $\left(r_{\max } \approx 0.6 \div 0.7\right)$, the correlation patterns are variable and differ from month to month contrary to the negative correlations for $\bar{w}^{*}$. In November (Fig. 9a) a narrow belt of positive correlations stretches from the Equator to the North Pole at $30 \mathrm{hPa}$. It is interesting to note that this feature is identical to the November correlation pattern between HF and $\bar{v}^{*}$ (Fig. 7a). From the following months January (Fig. 9b) with a wide area of positive correlations in the $\mathrm{NH}$ subtropics can be singled out. December, February and March (not shown) have two belts 

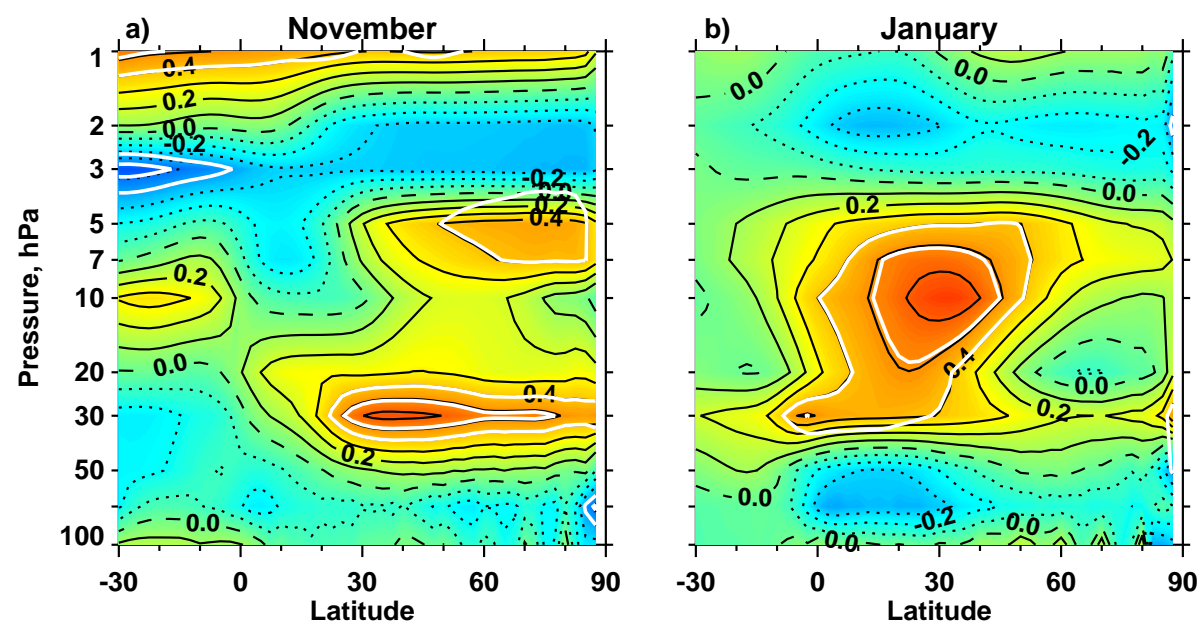

Fig. 9. Correlation between $\Delta \mathrm{O}_{3} / \Delta t\left(50^{\circ}-60^{\circ} \mathrm{N}\right)$ and $\bar{v}^{*}$ in (a) November and (b) January. $\bar{v}^{*}$ is averaged from 20th of previous month to 20th of given month. Contours and shading as in Fig. 5.

of significant correlations: one in the lower and another in the middle stratosphere that only is to some extent similar to November (Fig. 9a). Larger uncertainties in the calculated $\bar{v}^{*}$ (see Sect. 2) in comparison with $\bar{w}^{*}$ may explain why the positive correlations for $\bar{v}^{*}$ are nonuniform and differ from month to month while the negative correlations for $\bar{w}^{*}$ are almost similar.

We also examined the relationship between $\Delta \mathrm{O}_{3} / \Delta t$ and the residual streamfunction $\left(\bar{\psi}^{*}\right)$ which may be more appropriate as a single proxy than $\bar{w}^{*}$ or $\bar{v}^{*}$. The strongest positive correlations $\left(r_{\max } \approx 0.7 \div 0.75\right)$ between $\Delta \mathrm{O}_{3} / \Delta t$ and $\bar{\psi}^{*}$ (not shown) are rather stable for all months and located in the lower stratosphere (approximately 100-30 hPa) southward of the $50^{\circ}-60^{\circ} \mathrm{N}$ region chosen for $\Delta \mathrm{O}_{3} / \Delta t$. Hence using $\bar{\psi}^{*}$ to describe variability in $\Delta \mathrm{O}_{3} / \Delta t$ gives an identical result to that using $\bar{w}^{*}$.

We showed in the previous section that temperature tendencies are strongly coupled with the wave forcing. Ozone tendencies should also be coherent with $\Delta T / \Delta t$ because interannual variability of both is controlled by the mean meridional circulation. The averaging period for $\Delta T / \Delta t$ giving the best correlation with $\Delta \mathrm{O}_{3} / \Delta t$ is almost consistent with the averaging period for $\bar{w}^{*}$ (20th of previous month to 20th of given month) in October-January but is shifted forward by approximately $10-15$ days in February-March. Figure 10 shows correlations of the (a) November and (b) January $\Delta \mathrm{O}_{3} / \Delta t$ with $\Delta T / \Delta t$ averaged for 20 October-20 November and 15 December-15 January, respectively. The observed north-south dipole in the stratosphere exists in all months with the exception of December, similar to the structure of correlation between HF and $\Delta T / \Delta t$ in Fig. 6. By analogy with $\bar{w}^{*}$, the maximum of extratropical correlation is located south of $60^{\circ} \mathrm{N}$ while the strongest correlation of $\Delta T / \Delta t$ with $\mathrm{HF}\left(45^{\circ}-75^{\circ} \mathrm{N}, 100 \mathrm{hPa}\right)$ is found north of $60^{\circ} \mathrm{N}$ (Fig. 6). The explanation for the difference is the same as for $\bar{w}^{*}$ : HF over $45^{\circ}-75^{\circ} \mathrm{N}, 100 \mathrm{hPa}$ does not describe the residual circulation in midlatitudes as well. HF taken over regions with maximum correlation in Fig. 3 brings almost the same correlation patterns with $\Delta T / \Delta t$ as $\Delta \mathrm{O}_{3} / \Delta t$ in Fig. 10. The observed dipole is weaker in November (Fig. 10a) and becomes stronger in January (Fig. 10b) remaining similar in February and March. In December only the northward part of the dipole $\left(r_{\max }=0.45\right)$ centred at $50^{\circ} \mathrm{N}$ is observed. In this respect, December with weaker correlation between $\Delta \mathrm{O}_{3} / \Delta t$ and both $\mathrm{HF}$ and $\Delta T / \Delta t$ is sharply distinguished from other months but we could not find any reasonable explanation.

In the early stage of the ozone buildup the October $\Delta \mathrm{O}_{3} / \Delta t$ averaged over the North Pacific shows an small area of negative correlation with $\bar{w}^{*}$ in the polar lower stratosphere but no correlation with $\bar{v}^{*}$. Also $\Delta T / \Delta t$ averaged for 20 September-20 October correlates well $\left(r_{\max }=0.7\right)$ with the North Pacific $\Delta \mathrm{O}_{3} / \Delta t$ showing a north-south dipole in the lower stratosphere. Though interannual variability in both tendencies is controlled by the mean meridional circulation, $\Delta T / \Delta t$ as one more "proxy" for $\Delta \mathrm{O}_{3} / \Delta t$ explains $50 \%$ of the variance in ozone tendencies thus consistent with the results for HF and $\bar{w}^{*}$. As in the previous section, the NCEP/NCAR reanalysis shows similar results.

\section{Summary and discussion}

This study focuses on the wintertime ozone buildup in the $\mathrm{NH}$ midlatitudes $\left(50^{\circ}-60^{\circ} \mathrm{N}\right)$ during the October-March period and the statistical relationship of the buildup with the mean meridional circulation. The buildup begins locally in October when positive $\Delta \mathrm{O}_{3} / \Delta t$ appears over the North Pacific. Two processes can be responsible for the local beginning of the buildup: intensification of northward ozone transport confined in the Pacific and deepening of the Aleutian low leading to accumulation of ozone in the 

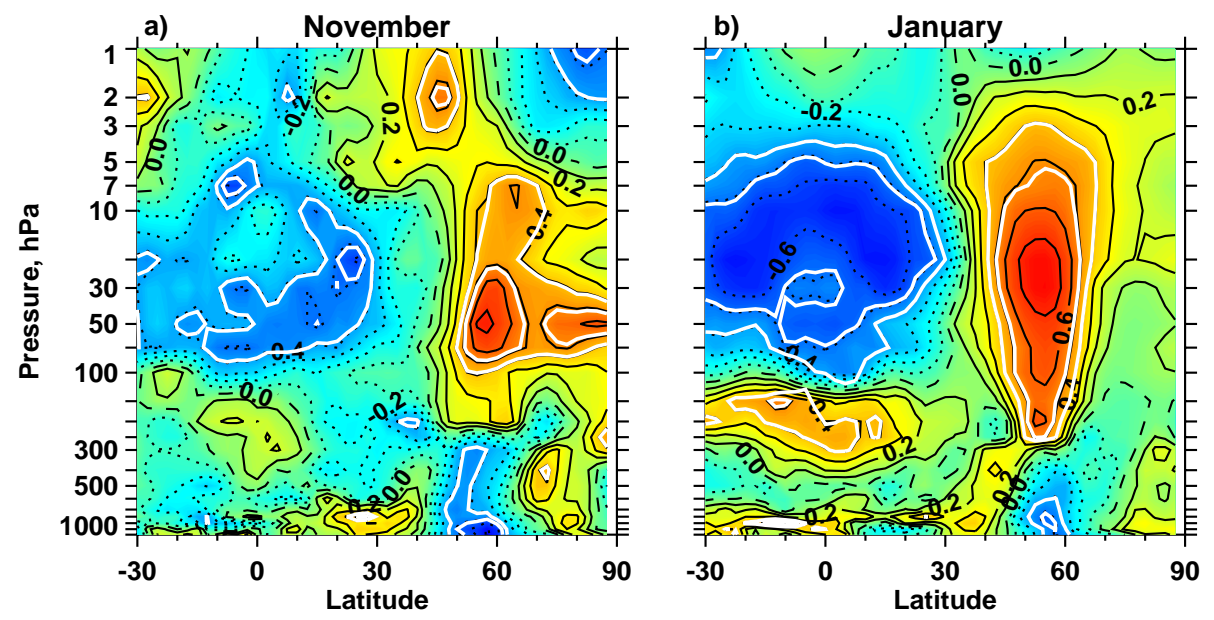

Fig. 10. Correlation between $\Delta \mathrm{O}_{3} / \Delta t\left(50^{\circ}-60^{\circ} \mathrm{N}\right)$ and $\Delta T / \Delta t$ in (a) November and (b) January. $\Delta T / \Delta t$ is averaged (a) for 20 October-20 November and (b) 15 December-15 January. Contours and shading as in Fig. 5.

lower stratosphere. At the same time presence of negative $\Delta \mathrm{O}_{3} / \Delta t$ over the opposite part of the NH gives the October zonal mean $\Delta \mathrm{O}_{3} / \Delta t$ close to zero that masks the local onset of the buildup in zonal mean $\Delta \mathrm{O}_{3} / \Delta t$. In November positive $\Delta \mathrm{O}_{3} / \Delta t$ spreads eastward and westward from the North Pacific and finally covers all NH midlatitudes in December. The observed development of the NH ozone buildup demonstrates the presence of zonal asymmetries in the Brewer-Dobson circulation which are especially noticeable in October. In the early and middle stages of the buildup (October-January), the longitude structure of $\Delta \mathrm{O}_{3} / \Delta t$ mirrors total ozone distribution (maxima and minima) which is related to quasi-stationary planetary waves in the lower stratosphere. However, during the final stage (February and March) $\Delta \mathrm{O}_{3} / \Delta t$ shows less resemblance with the planetary wave pattern which may be explained by export of ozone depleted air from the polar vortex into midlatitudes as well as the vortex breakup for March.

Several zonal mean parameters (eddy heat flux, temperature tendency, residual velocities and the residual streamfunction) associated with the mean meridional circulation are used to estimate the contribution from the mean meridional transport to interannnual variability of monthly $\Delta \mathrm{O}_{3} / \Delta t$. The correlation patterns between $\Delta \mathrm{O}_{3} / \Delta t$ and HF are not uniform during the buildup. It is most likely that the heightlatitude structure of zonal mean zonal wind defines the existence of the midlatitude or polar waveguides and consequently high correlations are located either equatorward or poleward of the edge of the polar vortex. At the same time in the equatorward position strong correlations are apparent almost throughout the stratosphere while in the poleward position they are apparent only in the lower stratosphere. As a consequence, $\mathrm{HF}$ averaged over the usual region $45^{\circ}-75^{\circ} \mathrm{N}$, $100 \mathrm{hPa}$ is not always an optimum proxy for total ozone variability in midlatitudes. Practically, in order to optimise HF as a proxy for a statistical model, it is necessary to examine, at first, where on the latitude-altitude cross section the strongest correlation between HF and ozone occurs.

From other parameters $\Delta T / \Delta t, \bar{w}^{*}$ and $\bar{\psi}^{*}$ show almost homogeneous high correlation patterns from month to month. For all months from November to March, maximum absolute values of correlation coefficients between zonal mean $\Delta \mathrm{O}_{3} / \Delta t$ and the parameters are close to 0.7 on average. Hence, assuming a linear relationship, half of the interannual variability in the $50^{\circ}-60^{\circ} \mathrm{N}$ zonal mean $\Delta \mathrm{O}_{3} / \Delta t$ for 1980-2002 can be explained by the mean meridional circulation. One partial exception here is December, in the middle stage of the buildup, when $\Delta T / \Delta t$ and HF have a weaker correlation $\left(r_{\max }=0.45\right)$ with $\Delta \mathrm{O}_{3} / \Delta t$ while $\bar{w}^{*}$ and $\bar{\psi}^{*}$ show a correlation $\left(|r|_{\max }=0.7\right)$ which is similar to that in other months. We have not found any explanation for this feature. The obtained half of the explained variance in $\Delta \mathrm{O}_{3} / \Delta t$ is lower than in the results of Salby and Callaghan (2002) and Weber et al. (2003) where total ozone was averaged over wider latitude belts including the polar region and $\Delta \mathrm{O}_{3} / \Delta t$ was calculated for the whole winter period. The explained variance in both studies is about $80 \%$. At the same time $50 \%$ of explained variance is higher than the results of Randel et al. (2002) for monthly mean zonal mean $\left(35^{\circ}-60^{\circ} \mathrm{N}\right)$ $\Delta \mathrm{O}_{3} / \Delta t$ where the explained variance is typically less than $50 \%$ and rather weak correlations were found in November and December. The results based on the NCEP/NCAR reanalysis show very good qualitative and quantitative agreement with the results based on the ERA-40, suggesting that the obtained results are independent of which dataset is chosen.

Finally, $\bar{w}^{*}$ or $\bar{\psi}^{*}$ look to be preferable to HF as proxies for statistical models describing total ozone in midlatitudes, since the correlation patterns and the maximum correlation coefficients between $\Delta \mathrm{O}_{3} / \Delta t$ and $\bar{w}^{*}$ or $\bar{\psi}^{*}$ are stable 
throughout winter. However the practical estimation of the residual circulation is not as simple as the HF calculation.

Acknowledgements. The authors thank the TOMS science team (NASA/GSFC), ECMWF and CPC for providing data and two anonymous reviewers for their helpful comments. The work of G. Nikulin is supported by the Swedish Research Council. The work of A. Karpechko is supported by the EU Commission under the project CANDIDOZ.

Edited by: V. Fomichev

\section{References}

Andrews, D. G., Holton, J. R., and Leovy, C. B.: Middle Atmosphere Dynamics, Academic Press, 489 pp., 1987.

Brasseur, G. and Solomon, S.: Aeronomy of the middle atmosphere, D. Reidel Publishing Company, 441 pp., 1986.

Brewer A. E.: Evidence for a world circulation provided by the measurements of helium and water vapour distribution in the stratosphere, Q. J. Roy. Meteor. Soc., 75, 351-363, 1949.

Dickinson, R. E.: Planetary Rossby waves propagating vertically through weak westerly wind wave guides, J. Atmos. Sci., 25, 984-1002, 1968.

Dobson G. M. B.: Origin of distribution of the polyatomic molecules in the atmosphere, Proc. Roy. Soc. London, 236A, 187-193, 1956.

Dunkerton, T.: On the mean meridional mass motions of the stratosphere and mesosphere, J. Atmos. Sci., 35, 2325-2333, 1978.

Eluszkiewicz, J., Crisp, D., Zurek, R., Elson, L., Fishbein, E., Froidevaux, L., Waters, J., Grainger, R. G., Lambert, A., Harwood, R., and Peckham, G.: Residual circulation in the stratosphere and lower mesosphere as diagnosed from Microwave Limb Sounder data, J. Atmos. Sci., 53, 217-240, 1996.

Eluszkiewicz, J., Crisp, D., Grainger, R. G.., Lambert, A., Roche, A. E., Kumer, J. B., and Mergenthaler, J. L.: Sensitivity of the residual circulation diagnosed from the UARS data to the uncertainties in the input fields and to the inclusion of aerosols, J. Atmos. Sci., 54, 1739-1757, 1997.

Fioletov, V. E. and Shepherd, T. G.: Seasonal persistence of midlatitude total ozone anomalies, Geophys. Res. Lett., 30(7), 1417, doi:10.1029/2002GL016739, 2003.

Frith, S., Stolarski, R., and Barthia, P.: Implications of Version 8 TOMS and SBUV data for long-term trend analysis, in: Proceedings of the Quadrennial Ozone Symposium-2004, edited by: Zerefos, C., 65-66, Athens, Greece, 2004.

Fusco, A. C. and Salby, M. L.: Interannual variations of total ozone and their relationship to variations of planetary wave activity, J. Climate, 12, 1619-1629, 1999.

Geller, M. A., Nash, E. R., Wu, M. F., and Rosenfield, J. E.: Residual circulations calculated from satellite data: their relations to observed temperature and ozone distributions, J. Atmos. Sci., 49, 1127-1137, 1992.

Gille, J. C., Lyjak, L. W., and Smith, A. K.: The global residual mean circulation in the middle atmosphere for the Northern winter period, J. Atmos. Sci., 44, 1437-1454, 1987.

Hadjinicolaou, P. and Pyle, J. A.: The impact of Arctic ozone depletion on northern middle latitudes: interannual variability and dynamical control, J. Atmos. Chem., 47, 25-43, 2004.
Holton, J. R., Haynes, P. H., McIntyre, M. E., Douglass, A. R., Rood, R. B., and Pfister, L.: Stratosphere-troposphere exchange, Rev. Geophys., 33, 403-439, 1995.

Hood, L. L. and Zaff, D. A.: Lower stratospheric stationary waves and the longitude dependence of ozone trends in winter, J. Geophys. Res., 100, 25 791-25 800, 1995.

Karpechko A., Kyro E., and Knudsen, B. M.: Arctic and Antarctic polar vortices 1957-2002 as seen from the ERA-40 reanalyses, in press, J. Geophys. Res., 2005.

Karpetchko, A. and Nikulin, G.: Influence of early winter upward wave activity flux on midwinter circulation in the stratosphere and troposphere, J. Climate, 17, 4443-4452, 2004.

Kurzeja, R. J.: Spatial variability of total ozone at high latitudes in winter, J. Atmos. Sci., 41, 695-697, 1984.

Ma, J., Waugh, D. W., Douglass, A. R., Kawa, S. R., Newman, P. A., Pawson, S., Stolarski, R., and Lin, S. J.: Interannual variability of stratospheric trace gases: The role of extratropical wave driving, Q. J. Roy. Meteor. Soc., 130, 2459-2474, 2004.

Murgatroyd, R. J. and Singleton, F.: Possible meridional circulations in the stratosphere and mesosphere, Q. J. Roy. Meteor. Soc., 87, 125-135, 1961.

Nagatani, R. M. and Miller, A. J.: The influence of lower stratosphere forcing on the October Antarctic ozone decrease, Geophys. Res. Lett., 14, 202-205, 1987.

Nash, E. R., Newman P. A., Rosenfield J. E., and Schoeberl, M. R.: An objective determination of the polar vortex using Ertel's potential vorticity, J. Geophys. Res., 101, 9471-9478, 1996.

Newman, P. A. and Rosenfield, J. E.: Stratospheric thermal damping times, Geophys. Res. Lett., 24 433-24 436, 1997.

Newman, P. A. and Nash, E. R.: Quantifying the wave driving of the stratosphere, J. Geophys. Res., 105, 12 485-12 497, 2000.

Newman, P. A., Nash, E. R., and Rosenfield, J. E.: What controls the temperature of the Arctic stratosphere during the spring?, J. Geophys. Res., 106, 19999-20 010, 2001.

Olaguer, E. P., Yang, H., and Tung, K. K.: A reexamination of the radiative balance of the stratosphere, J. Atmos. Sci., 49, 1242 1263, 1992.

Plumb, R. A. and Eluszkiewicz, J.: The Brewer-Dobson circulation: dynamics of the tropical upwelling, J. Atmos. Sci., 56, 868-890, 1999.

Randel, W. J.: Global variation of zonal mean ozone during stratospheric warming events, J. Atmos. Sci., 50, 3308-3321, 1993.

Randel, W. J., Wu, F., and Stolarski, R.: Changes in column ozone correlated with the stratospheric EP flux, J. Meteor. Soc. Japan, 80, 849-862, 2002a.

Randel, W. J., Garcia, R. R., and Wu, F.: Time-dependent upwelling in the tropical lower stratosphere estimated from the zonal-mean momentum budget, J. Atmos. Sci., 59, 2141-2152, 2002b.

Salby, M. L. and Callaghan, P. F.: Interannual changes of the stratospheric circulation: relationship to ozone and tropospheric structure, J. Climate, 15, 3673-3685, 2002.

Shine, K.: The middle atmosphere in the absence of dynamical heat fluxes, Q. J. Roy. Meteor. Soc., 113, 603-633, 1987.

Shine, K.: Sources and sinks of zonal momentum in the middle atmosphere diagnosed using the diabatic circulation, Q. J. Roy. Meteor. Soc., 115, 265-292, 1989.

Solomon, S., Kiehl, J. T., Garcia, R. R., and Grose, W.: Tracer transport by the diabatic circulation deduced from satellite observations, J. Atmos. Sci., 43, 1603-1617, 1986. 
SPARC; SPARC intercomparison of middle-atmosphere climatologies, SPARC Rep.3, 96 pp., 2002.

Weber M., Dhomse, S., Wittrock, F., Richter, A., Sinnhuber, B.-M., and Burrows, J. P.: Dynamical control of NH and SH winter/ spring total ozone from GOME observations in 1995-2002, Geophys. Res. Lett., 30(11), 1583, doi:10.1029/2002GL016799, 2003. 